\title{
Synthesis, characterization and antimicrobial activity of the micro/nano structured biogenic silver doped calcium phosphate
}

\author{
N. Supraja • T. N. V. K. V. Prasad • \\ Ernest David
}

Received: 9 November 2014/ Accepted: 1 February 2015/Published online: 18 February 2015

(c) The Author(s) 2015. This article is published with open access at Springerlink.com

\begin{abstract}
Scale formation in PVC pipelines reduces the water flow efficiency and enhances microbial contamination. A bio-based composite material comprising of silver doped calcium phosphate (Cp-Ag) was synthesized using a simple technique (photo catalysis) and herein, we report for the first time on preparation and evaluation of the antimicrobial efficacy of silver doped calcite extracted from the scale in drinking water pipe lines. Five concentrations of silver doped calcite materials viz,5, 10, 15, 20 and $25 \mathrm{ppm}$ were prepared using chemical ammonia mediated synthetic method. The material $\mathrm{Cp}-\mathrm{Ag}$ was characterized by using the techniques UV-Visible spectroscopy, X-ray diffraction, Fourier transform infrared spectroscopy, Scanning electron microscopy, Raman spectroscopy, Thermo gravimetric analysis, X-ray photo electron spectroscopy (XPS), Nuclear magnetic resonance spectrometer and X-ray flouresence microscopy (XRF). Typical rhombohedral structure of the silver doped calcite was observed. XRF and XPS studies confirmed the presence of both calcium and silver in the composite material (Cp-Ag). The silver doped calcite material exhibited enhanced inhibition against Escherichia coli and staphylococcus aureus (Kirby-Bauer discs diffusion assay) which is also dependent on the concentration of the Cp-Ag material.
\end{abstract}

\section{N. Supraja · E. David $(\bowtie)$}

Department of Biotechnology, Thiruvalluvar University,

Vellore 632001, Tamil Nadu, India

e-mail: ernestdavid2002@yahoo.com

T. N. V. K. V. Prasad ( $ه)$

Nanotechnology Laboratory, Institute of Frontier Technology, Regional Agricultural Research Station, Acharya N G Ranga Agricultural University, Tirupati 517 502, Andhra Pradesh, India e-mail: tnvkvprasad@gmail.com
Keywords Calcium phosphate $\cdot$ Silver nanoparticles · Antimicrobial activity Ammonium hydroxide

\section{Introduction}

Scales formed in drinking water pipes mostly consists of tubercles formed via precipitation and re-precipitation mechanisms of pipe-originating nucleating elements such as $\mathrm{PVC}$, aluminum $(\mathrm{Al})$, copper $(\mathrm{Cu})$, iron $(\mathrm{Fe})$, and lead $(\mathrm{Pb})$ (Renner 2008). Alkaline or calcareous scales are the most commonly observed types of pipe scales composed of minerals, such as, calcium carbonate, goethite, magnetite, green rust and amorphous Fe phases (Edwards et al. 2000). Scales formed in drinking water PVC pipes consists of Calcium phosphate, Calcium carbonate etc. Calcium phosphate is bioactive and supports the regeneration of bone on the substrate; it is mainly used for the bio-medical field, in particular, bio-implant materials such as orthopedic, dental and maxillofacial application.

One of the interesting and challenging fields in materials science is the one involving biomaterials. The scientific research takes a lot of effort to provide new and improved biomaterials with specific applications in medicine (Dahl et al. 2007; Hutchison 2008), antimicrobial research in particular. The continuing appearance of antibiotic resistance in microorganisms challenges the scientific community to constantly develop new bioactive compounds and drug targets with high biocompatibility and antibacterial properties. Nowadays, the scientists are looking towards developing new bioactive compounds with silver at a nanometric scale. Although, the exact mechanism of the antibacterial action of $\mathrm{Ag}$ nanoparticles is not completely understood, yet there are reports in the literature that show that electrostatic attraction between negatively charged 
bacterial cells and positively charged nanoparticles are crucial for the activity of nanoparticles as bactericidal materials (Khaydarov et al. 2008; Hamouda and Baker 2000). Several possible mechanisms have been proposed that involve the interaction of silver with biological macromolecules (Sharma et al. 2009) such as enzymes and DNA through an electron-release mechanism (Jiang et al. 2004). It is believed that DNA loses its replication ability and cellular proteins are inactivated upon $\mathrm{Ag}^{+}$treatment (Feng et al. 2000). In addition, it has also shown that $\mathrm{Ag}^{+}$binds to functional groups of proteins, resulting in protein denaturation (Rastogi et al. 2011). To obtain high biocompatibility and optimal antibacterial properties of the new compounds, silver ions were embedded in materials with bio-properties (Ciobanu et al. 2011). One of the widely studied biomaterial so far is the hydroxyapatite (HAp), a bioceramic material from the family of apatites with the general formula $\mathrm{Ca}_{10}\left(\mathrm{PO}_{4}\right) 6(\mathrm{OH})_{2}$ (Vallet-Regi and Gonzalez-Calbet 2004; Costescu et al. 2010). Being the main inorganic constituent in human bones and teeth, HAp is widely used in medical applications such as implants, coatings, prostheses. It is due to the high demand for new biocompatible and antibacterial materials, the scientists thought of immobilizing antibacterial metals in the matrix of biomaterials.

This bioactive calcium phosphate was synthesized by various methods such as sol-gel, hydrothermal and chemical precipitation. Recently, methods were developed to synthesize microbial resistance calcium phosphate nanomaterial incorporated with metal nanoparticles like, Ag, $\mathrm{Au}, \mathrm{MgO}, \mathrm{ZnO}$ and $\mathrm{TiO}_{2}$ which exhibited potential antimicrobial properties against an array of microbes. In the present study, silver doped calcium phosphate (scale) was synthesized using chemical ammonia. The resultant product was characterized by following analytical techniques such as FT-IR, XRF, XRD, RAMAN, SEM and TGA. The bio-formation and generation of calcium phosphate was characterized by Solid state NMR $\left(\mathrm{C}^{13}, \mathrm{P}^{31}\right)$. The antimicrobial activity of prepared composite material was evaluated against gram positive (Staphylococcus aureus) and gram negative (Escherichia coli) bacterial species. To the best of our knowledge, this is the first report on preparation of $\mathrm{Ag}$-doped biogenic calcium phosphate composite material and evaluation of their antimicrobial activity.

\section{Materials and methods}

Calcium phosphate scale samples were taken from drinking water PVC pipelines. The silver nitrate was purchased from Sigma-Aldrich. The E. coli and S. aureus were procured from the local sources. The bacteria growth media LB agar was purchased from Fisher Scientific (Waltham, MA).

\section{Collection of scale sample}

The PVC scale sample was collected from Tirupathi, (Chittoor District) Andhra Pradesh, India. The samples were collected from drinking water PVC pipelines and taken in the sterile container. The collected samples were in crystalline form. These samples were stored in an ice box and transported for further microbiological characterization in the laboratory.

\section{Synthesis of silver doped calcium phosphate (Cp-Ag)}

$1 \mathrm{gm}$ of Calcium phosphate from scale sample is taken and mixed with $50 \mathrm{ml}$ of distilled water and different concentrations $(5,10,15,20$ and $25 \mathrm{ppm})$ of silver nitrate are dissolved in it separately and the final volume of $100 \mathrm{ml}$ was made. Then chemical ammonium hydroxide was added dropwise until the precipitation dissolves and was allowed for stirring for $3 \mathrm{~h}$ and was exposed to sunlight for photo-reduction of silver, then cooled to room temperature and centrifuged at $6,000 \mathrm{rpm}$ for $30 \mathrm{~min}$. The pellet was washed with distilled water to remove excess ammonium, calcium and phosphate ions. The precipitate was subjected to annealing at $80^{\circ} \mathrm{C}$ for $1 \mathrm{~h}$ and the collected powder was used for further studies.

\section{Characterization of silver doped scale sample materials}

$\mathrm{UV}-\mathrm{Vis}$ spectral analysis

The UV-Vis absorbance spectrum represents the characteristic absorbance of a given material. The UV-Vis spectrum of this solution was recorded in spectra 50 ANALYTIKJENA Spectrophotometer, from 250 to $800 \mathrm{~nm}$.

Fourier transform infrared (FT-IR) spectroscopic analysis

The biochemical changes in the solution have been characterized by FT-IR, which is generally used to detect the functional group of compound (Bruker, Tensor 27-model). The FT-IR spectrum is taken in the mid IR region of $400-4,000 \mathrm{~cm}^{-1}$ with the spectral resolution $4 \mathrm{~cm}^{-1}$. The sample was directly mixed in the $\mathrm{KBr}$ powder and the spectrum was recorded in the transmittance mode. 
Scanning electron microscopy (SEM)—surface morphology studies

The surface morphological studies of the silver doped scale $\left(\mathrm{CaPO}_{4}\right)$ samples were carried out with scanning electron microscope (SEM) (Hitachi's SU6600) at magnification ranging from 10 to $600,000 \times$ operated at an accelerating voltage of $30 \mathrm{kV}$.

Nuclear magnetic resonance spectroscopic studies

Nuclear magnetic resonance spectroscopy is an analytical technique that exploits the magnetic properties of certain nuclei. It relies on the phenomenon of nuclear magnetic resonance and can provide detailed information about the structure, dynamics, reaction state, and chemical environment of atoms in a molecule. $1 \mathrm{~mL}$ of Bio-electrochemical products was taken in NMR tube separately and adds $0.5 \mathrm{~mL}$ of $\mathrm{D}_{2} \mathrm{O}$. The sample was run in $90 \% \mathrm{H}_{2} \mathrm{O}$ and $10 \% \mathrm{D}_{2} \mathrm{O}$ mode (BRUKER 400 UTLRA SHIELD NMR). The solid state NMR molecular structure of $\mathrm{C}^{13}$ and $\mathrm{P}^{31}$ were studied.

XRD (structural analysis of nanoparticles)

The XRD patterns of the silver and silver doped calcium phosphate composite materials were recorded using computer controlled XRD-system (JEOL: JPX-8030 with $\mathrm{CuK} \alpha$ radiation ( $\mathrm{Ni}$ filtered $=13,418 \AA$ ) at the range of $40 \mathrm{kV}, 20 \mathrm{~A})$. The 'peak search' and 'search match' program built in software (syn. master 7935) was used to identify the peaks in XRD patterns.

XRF (X- ray fluorescence microscopic studies)

In X-ray fluorescent microscope (XGT-2700 X-ray analytical microscope, HORIBA, Japan), the silver doped calcium phosphates were analyzed for the elemental presence of silver, calcium and phosphorous in the doped composite material.

\section{Thermo gravimetric analysis (TGA)}

The thermal behavior of silver doped calcium phosphate nanoparticles was studied by thermal gravity analysis (TGA). Samples were scanned (TA Instruments Model SDT Q600) from room temperature to $800{ }^{\circ} \mathrm{C}$ and the yield of the product was also recorded.

\section{Laser Raman spectroscopic measurements}

A Raman spectrophotometer is to detect the maximum sensitivity of the product. The surface defects and $\mathrm{sp}^{2}$ hybridization of grapheme sheets were determined by LASER RAMAN spectroscopy (RFS 100/S-Bruker, Inc., Karlsruhe, Germany, Matlab 6.0 software) at the excitation wavelength of $633 \mathrm{~nm}$ with exposure time of $10 \mathrm{~s}(100 \%$ intensity).

\section{X-RAY photoelectron spectroscopy}

The surface chemistry of the silver doped scale composite powders was investigated using X-ray photoelectron spectroscopy (XPS) measurements. The XPS spectrum was taken by ESCA model VG 3000 SYSTEM. The base pressure in the experimental chamber was in the low $10^{-9}$ mbar range. The spectrum was collected using $\mathrm{Mg} \mathrm{Ka}$ $(1253.6 \mathrm{eV})$ radiation and the overall energy resolutions were $0.8 \mathrm{eV}$. Samples of $0.6 \mathrm{~cm}^{2}$ were used. Survey spectrum was recorded for the samples in the $\mathrm{O}-1100 \mathrm{eV}$ kinetic energy by $1 \mathrm{eV}$ steps while high resolution scan with $0.1 \mathrm{eV}$ steps were conducted over the following regions. The angle of the incidence of the x-ray beam with the specimen normal was $51.5^{\circ}$. In cases when the peaks were low in amplitude, the Savitsky-Golay smoothing routine was used to help determine the peak binding energies, typically measureable to $0.1 \mathrm{eV}$ on this system. The XPS surface composition was calculated based on the Scofield cross-sectional values accounting for the instrumental transmission function in the FAT mode of operation.

\section{Zeta potential analyzer for synthesized nanoparticles}

The aqueous suspension of the synthesized nanoparticles was filtered through a $0.22 \mu \mathrm{m}$ syringe driven filter unit and the size of the distributed nanoparticles were measured by using the principle of dynamic light scattering (DLS) technique using nanopartica (HORIBA,SZ-100) compact scattering spectrometer.

Antimicrobial activity of silver doped calcium phosphate $(\mathrm{Cp}-\mathrm{Ag})$ composite material

To examine the antimicrobial effect of the composite calcium phosphate silver doped on E. coli and $S$. aureus modified Kirby-Bauer disc diffusion assay was used as follows. E. coli and S. aureus was incubated at $37^{\circ} \mathrm{C}$ in $14 \mathrm{ml} \mathrm{BD}$ falcon tube to an approximate concentration of 107 colony forming units $(\mathrm{CFU}) / \mathrm{ml}$. A lawn of the bacteria was placed on sterile McConkey agar Petri dish plates instead of commonly used Mueller-Hinton agar, for the ease of visualization of distinctly pink $E$. coli colonies bacteria. The lawns were plated using a sterile cotton swabs. Two sets of sterile circular disc filter papers were placed on the surface of two agar plates. In the first plate labeled as a, 
five circular disc papers were placed on the $E$. coli lawn. These disc papers were impregnated with $5 \mu \mathrm{l}$ of $5 \mathrm{ppm}$ of silver doped calcium phosphate composite material. Then $5 \mu \mathrm{l}$ of $10,15,20$ and $25 \mathrm{ppm}$ of different concentrations also checked by in vitro method using calcium phosphate as silver doping agent. Other in the second plate labeled as plate $\mathrm{B}$, each of the five discs papers were impregnated with $5 \mu \mathrm{l}$ of $5 \mathrm{mg}$ of the composite calcium phosphate silver doped. Then $5 \mu \mathrm{l}$ of $10,15,20$ and $25 \mathrm{ppm}$ of different concentrations also checked by in vitro method using calcium phosphate as silver doping agent same procedure used for $S$. aureus. The plates were incubated overnight at $37^{\circ} \mathrm{C}$. The zone of inhibition was observed and digital images of the plates were taken.

\section{Results and discussion}

$\mathrm{UV}-\mathrm{Vis}$ spectral analysis

The UV-vis absorption spectrum of the synthesized silver doped scale sample at different concentrations is presented in Fig. 1, which is the UV spectrum of doped $\mathrm{AgNO}_{3}$ processed without organic or chemical reducing agent. There is a maximum absorption at about $450 \mathrm{~nm}$ which matches with that for $\mathrm{AgNO}_{3}$ seen in $25 \mathrm{ppm}$ of silver doped scale. This is an indication that $\mathrm{AgNO}_{3}$ without organic or chemical reducing agents does not result in the production of silver nanoparticles. The UV absorption spectrum $20 \mathrm{ppm}$ silver doped scale absorption seen at $430 \mathrm{~nm}$. A minimum UV absorption peak exists at $370 \mathrm{~nm}$ that signify the disappearance of the dielectric function of silver at $5 \mathrm{mg}$. A single prominent broad peak with a maximum at 416 and $390 \mathrm{~nm}$ was observed, which corresponds to the typical surface Plasmon resonance (SPR) of spherical silver nanoparticles at 10 and $15 \mathrm{ppm}$. In these $\mathrm{UV}-\mathrm{Vis}$ spectra, there were no peaks located around 335

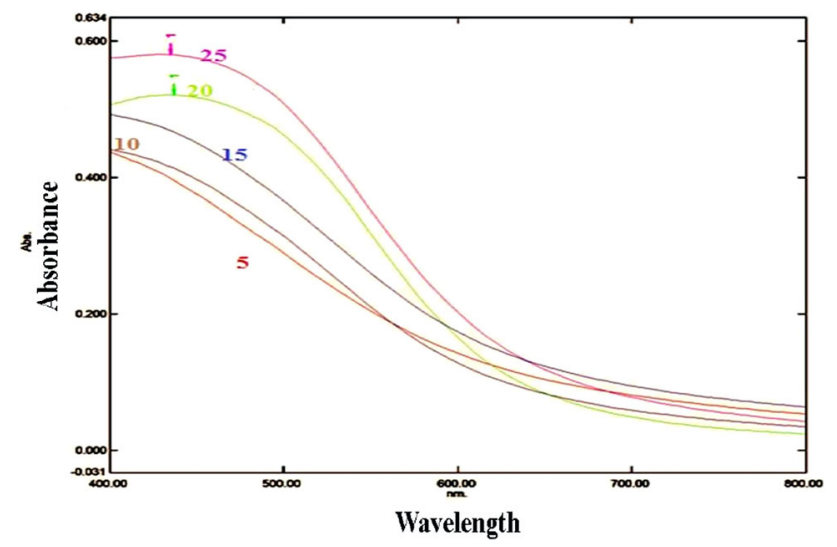

Fig. 1 UV-visible spectroscopy of silver doped scale $\left(\mathrm{CaPO}_{4}\right)$ sample at different concentrations $(5,10,15,20,25 \mathrm{ppm})$ and $560 \mathrm{~nm}$, indicating the complete absence of particle aggregates or clusters. Hence, silver nanoparticles formed are highly stable and well dispersed. The intensity of the absorption peaks increased with increasing concentration of the nanocomposite in solution.

\section{FT-IR analysis}

The interface between bio-organic functional groups and metal nanoparticles were illustrated by FT-IR spectrum. The peaks at $3,429 \mathrm{~cm}^{-1}$ were assigned to the stretching vibrations of primary, secondary amines and hydroxyl group, respectively. The peaks at $1,605 \mathrm{~cm}^{-1}$ corresponded to $\mathrm{C}=\mathrm{O}$ stretching vibrations of aromatic and aliphatic amines, respectively. The peaks were observed at 1,078 which can be assigned to the $(\mathrm{C}=\mathrm{O})$ groups. In addition to this band at $530 \mathrm{~cm}^{-1}$ corresponds to metal binding carboxylic ( $\mathrm{M} \leftrightarrow \mathrm{C} \equiv \mathrm{O})$ groups. Whereas bioreductant silver nanoparticles shows the same bio-organic functional groups peaks (Fig. 2), the nanoparticles are bound to the functional organic groups (carboxyl and amine) from the silver doped scale content. This functional group may act as template reducing and capping of nanocrystals, which with the observation made by FT-IR results. It clearly indicates that biosynthesis of silver nanoparticles and carboxylic groups are known to coordinate with metal ions which may act as a nucleation site for nanoparticles formation. It is evident from the FT-IR data that the silver vibrational mode was more prominently observed, and this clearly concludes a strong doping between $\mathrm{Ag}$ and scale $\left(\mathrm{CaPO}_{4}\right)$ nanocomposite materials.

\section{XRD analysis}

The $2 \theta \mathrm{X}$-ray diffraction patterns of as prepared synthesized silver nanoparticles doped scale. The X-ray patterns of these samples are compared with the Jade library Journal of chemical powder diffraction spectroscopy (JCPDS) $\mathrm{X}$-ray patterns of calcite and silver. The eight most prominent characteristic peaks of scale sample at $2 \theta=26.0,29.4,32.5,33.0,34.4,40.5$ and $44.5{ }^{\circ} \mathrm{C}$ were corresponding to the crystal faces of ( $\left(\begin{array}{lll}1 & 0 & 4\end{array}\right),\left(\begin{array}{lll}1 & 1 & 0\end{array}\right)$ and $\left(\begin{array}{lll}1 & 1 & 3\end{array}\right)$ of calcium phosphate scale with JCPDS card (file No. 47-1743) as indicated in (Fig. 3a) which confirms the rhombohedral crystalline structure of the calcite, one of the three and most stable phase of calcium phosphate. (Figure $3 \mathrm{~b}$ ) shows the X-ray diffraction pattern of silver nanoparticles with two strong distinguishing peaks at $2 \theta=37.2^{\circ} \mathrm{C}$ and $44.2^{\circ}$ corresponds to the Braggs crystal faces of $\left(\begin{array}{lll}1 & 1 & 1\end{array}\right)$ and (2 00 0) (JCPDS \# 04-0783) confirming characteristic face-centered cubic structure showing that silver. 
Fig. 2 FT-IR spectroscopy of silver doped scale $\left(\mathrm{CaPO}_{4}\right)$ sample at different concentrations $(5,10,15,20$, $25 \mathrm{ppm})$

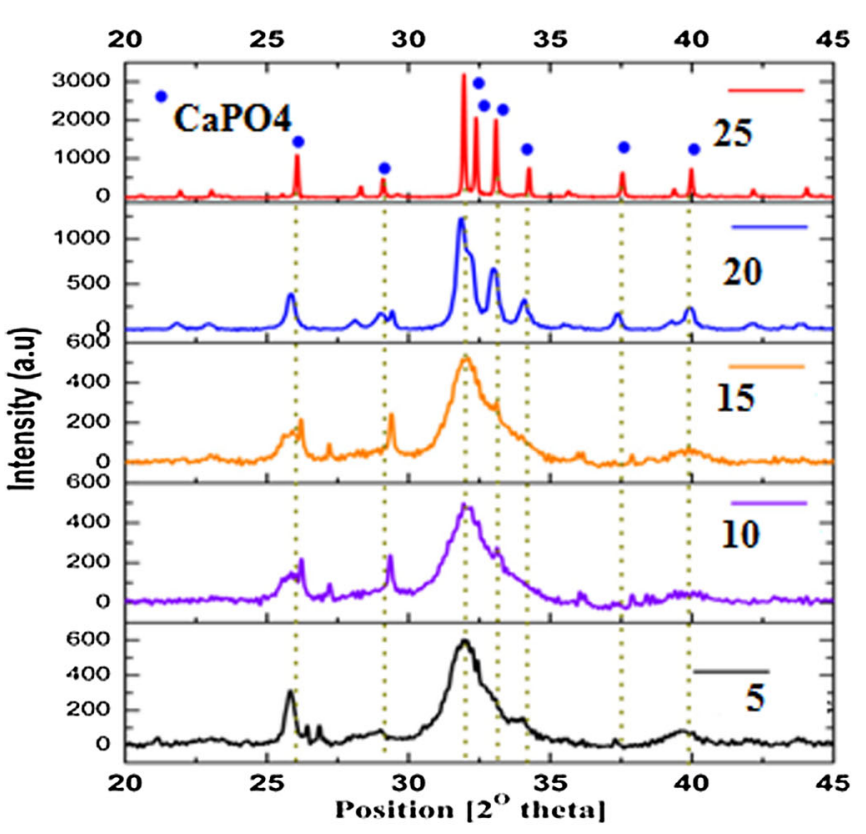

(a)

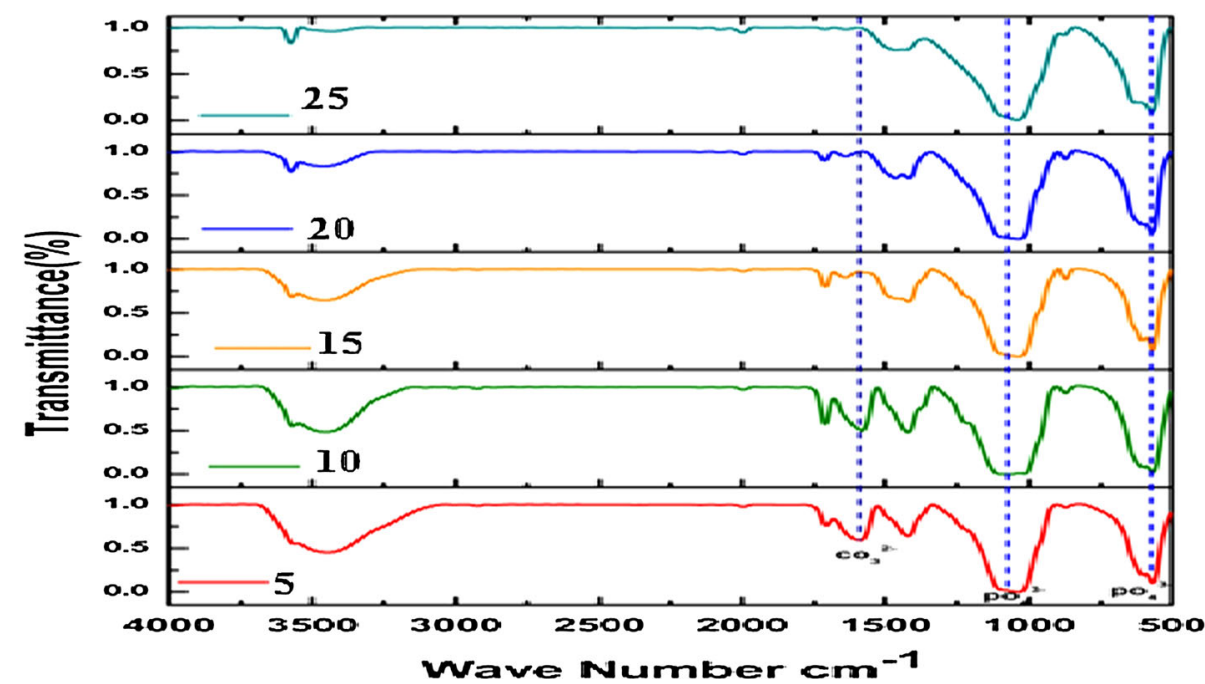

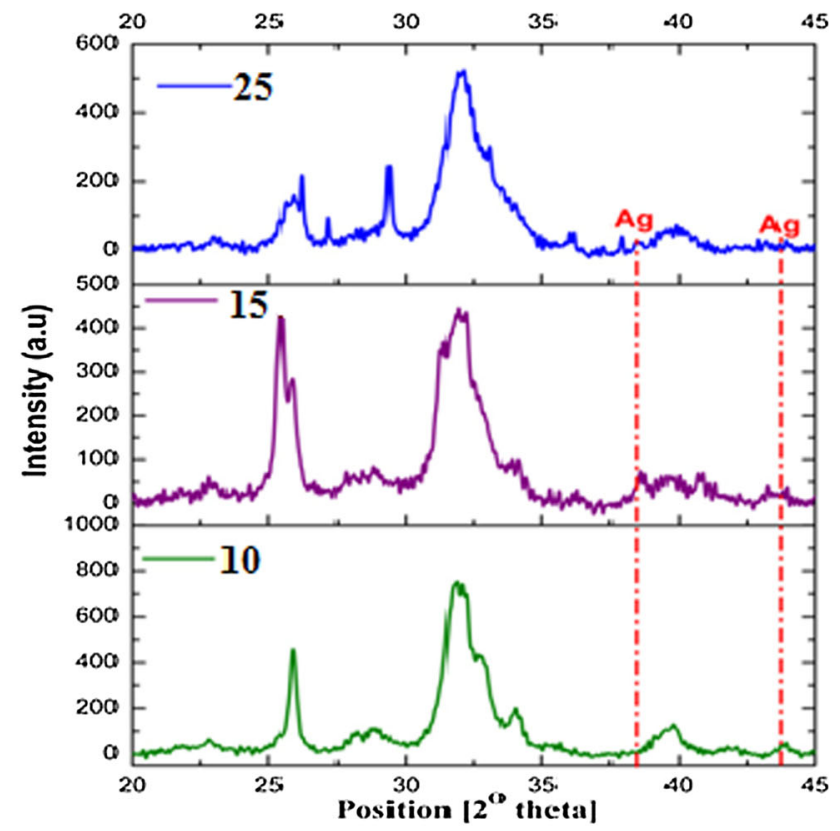

(b)

Fig. 3 XRD micrograph of silver doped scale $\left(\mathrm{CaPO}_{4}\right)$ sample at different concentrations $(5,10,15,20,25 \mathrm{ppm})$

\section{Solid state $\mathrm{P}^{31} \mathrm{NMR}$ analysis}

The synthesized silver doped scale sample (calcium phosphate) were analyzed for the presence of the silver doped phosphate in different concentrations of silver, the powder form of silver doped calcium phosphate shows the two adjacent peaks at -1.87 and -3.48 at 5 and $10 \mathrm{ppm}$ of silver doped $\mathrm{CaPO}_{4}-0.255$ and -3.355 are two peaks at $15 \mathrm{ppm}$. The two peaks merge and a single peak appears in -1.70 at $20 \mathrm{ppm}$. The peak shifts to -2.33 . At $25 \mathrm{ppm}$ the single peak at -1.95 appeared with high intensity and confirmed the presence of silver doped calcium phosphate (Fig. 4).
Laser Raman spectral analysis

The Raman spectrum shows prominent vibrational band related to silver doped scale samples. (Figure 5) shows the major peak, raised from $961 \mathrm{~cm}^{1}$, which shows the presence of silver doped $\mathrm{PO}_{4}{ }^{3-}$ group at $5 \mathrm{ppm}$, is very small and the disturbance of the peaks around the major peak is at 10,15 and $20 \mathrm{ppm}$ due the elimination of the hydroxide and carbonate groups. By increasing the concentration of silver, the intensity of the peak increases and at $25 \mathrm{ppm}$ the linear peak appears without any disturbance peak around it. In the typical spectrum from scale sample, the band centered at $961 \mathrm{~cm}^{-1}$ corresponds to the symmetric stretching 


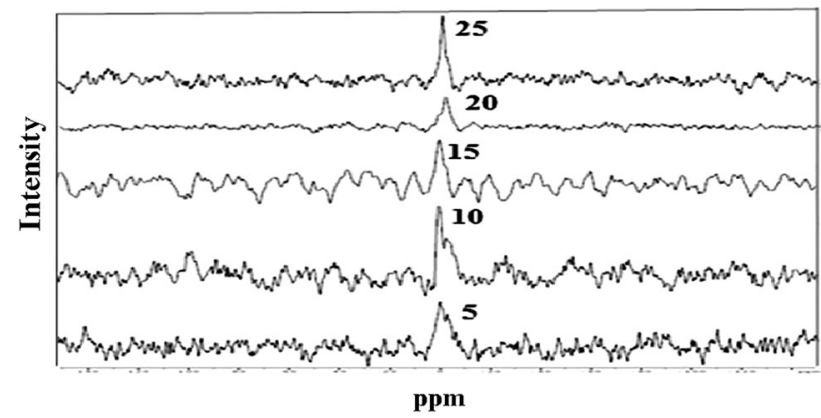

Fig. 4 NMR analysis of Silver doped scale $\left(\mathrm{CaPO}_{4}\right)$ sample at different concentrations $(5,10,15,20,25 \mathrm{ppm})$ at $\mathrm{P}^{31}$

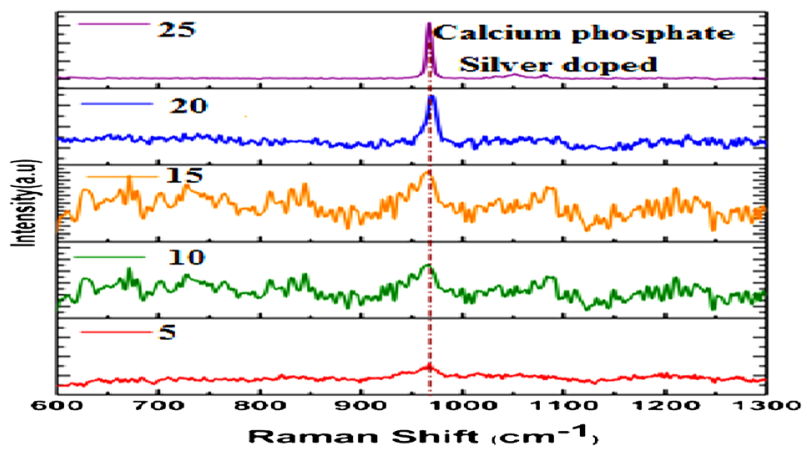

Fig. 5 RAMAN analysis of silver doped scale $\left(\mathrm{CaPO}_{4}\right)$ sample at different concentrations $(5,10,15,20,25 \mathrm{ppm})$

vibration of phosphate $\left(\mathrm{PO}_{4}^{3}\right)$. The peak at $1,071 \mathrm{~cm}^{-1}$ was formed by the silver doped calcium carbonate $\left(\mathrm{CaCO}_{3}{ }^{2-}\right)$ vibrational mode (Combes and Rey 2010).

TGA analysis

The purity of the silver nanoparticles doped scale sample $\left(\mathrm{CaPO}_{4}\right)$ was characterized by TGA and presented in (Fig. 6). From this data, it can be observed that three distinct slopes of weight loss process from places at 99, 200 and $445^{\circ} \mathrm{C}$. The curve shows $200{ }^{\circ} \mathrm{C} \mathrm{OH}$ groups. Below $200{ }^{\circ} \mathrm{C}$ in the biomass $445{ }^{\circ} \mathrm{C}$ was assigned to carbon contents present in the nanoparticles. The TGA shows that metal surface desorption of bio-organic substance $(4.20 \%)$ is present in the sample. It is negligible for the bio-impurities present in the sample. The impurities can act as nucleation sites and capping agent for nanoparticles. Since, biomass has large number of scale salts component, $95 \%$ purity of silver nanoparticles was harvested by sonication method.

\section{SEM analysis}

The morphology of dried silver doped calcium phosphate scale sample at different concentrations shows (Fig. 7) the crystalline nature of calcium phosphate by formation of repetitive layers in the silver doped material and the silver ion is deposited on the crystals on the scale. The size of the crystals were noticed to be approximately $1-10 \mu \mathrm{m}$. The higher magnification SEM image clearly shows silver doped $\mathrm{CaPO}_{4}$ crystals. These are generally either aggregates of planer, spherical, elongated crystals, or cubicshaped crystals.

\section{XRF (X-ray fluorescence) analysis}

XRF spectrum of silver doped calcium phosphate consists of Elemental maps for calcium $(\mathrm{Ca})$, phosphor $(\mathrm{P})$, and silver $(\mathrm{Ag})$ in the samples which are confirmed (Fig. 8). But the highest peaks were raised highly at $\mathrm{Ca}$ region. Then next $\mathrm{P}$ peaks were identified and a small peak of silver is identified finally. So, these results indicate that silver is doped into $\mathrm{CaPO}_{4}$ scale samples.

\section{XPS analysis}

The XPS wide spectrum in (Fig. 9) is a representation of silver doped scale sample. This spectrum provides vital information on the structure and chemical state of silver and scale sample (calcium phosphate). The spectrograph shows that the sample is made up of calcium, oxygen and silver with no impurities. The survey XPS spectra in the binding energy range up to $12,000 \mathrm{eV}$ identified peaks corresponding to $\mathrm{Ca}, \mathrm{C}, \mathrm{O}$ and $\mathrm{P} . \mathrm{Ca}_{2} \mathrm{P}, \mathrm{O} 1 \mathrm{~s}, \mathrm{C} 1 \mathrm{~s}$ spectra for silver doped scale sample from drinking water pipeline. There is a doublet around $363-379 \mathrm{eV}$ which has binding energies at 374 and $379 \mathrm{eV}$ which corresponds to silver. The peak at $350.6 \mathrm{eV}$ is an indication of the existence of one chemical state by calcium in the sample. The calcium peak at $358 \mathrm{eV}$ and $\mathrm{O} 1 \mathrm{~s}$ peak at 528 were assigned to $\mathrm{CaPO}_{4}$. The oxygen peak at $538 \mathrm{eV}$ is attributed to oxygen in carbonate. The O1s peak revealed two peaks at 528 and $538 \mathrm{eV}$ corresponding to oxygen in $\mathrm{CaPO}_{4}$ and $\mathrm{Ca}_{3} \mathrm{P}_{2} \mathrm{O}_{7}$, respectively.

\section{Zeta potential analysis}

Zeta potential is one of the important parameters in determining the dispersion state of the hydrosol (nanoparticulate solution). It indicates the overall charge that the particle acquires in a particular medium and the charge present on the surface of the nanoparticles is causative for the existed repulsive forces between them. In general, the nanoparticles are reported to be stable if the minimum charge around them is $-30 \mathrm{mV}$. The measured zeta potential of the silver doped ( $25 \mathrm{ppm})$ calcium phosphate was $-16.9 \mathrm{mV}$ (Fig. 10) indicating an anionic charge on the surface of the composite material. 
Fig. 6 TGA analysis of silver doped scale $\left(\mathrm{CaPO}_{4}\right)$ sample at 25 ppm concentration

Fig. 7 SEM images of silver doped scale $\left(\mathrm{CaPO}_{4}\right)$ sample at different concentration
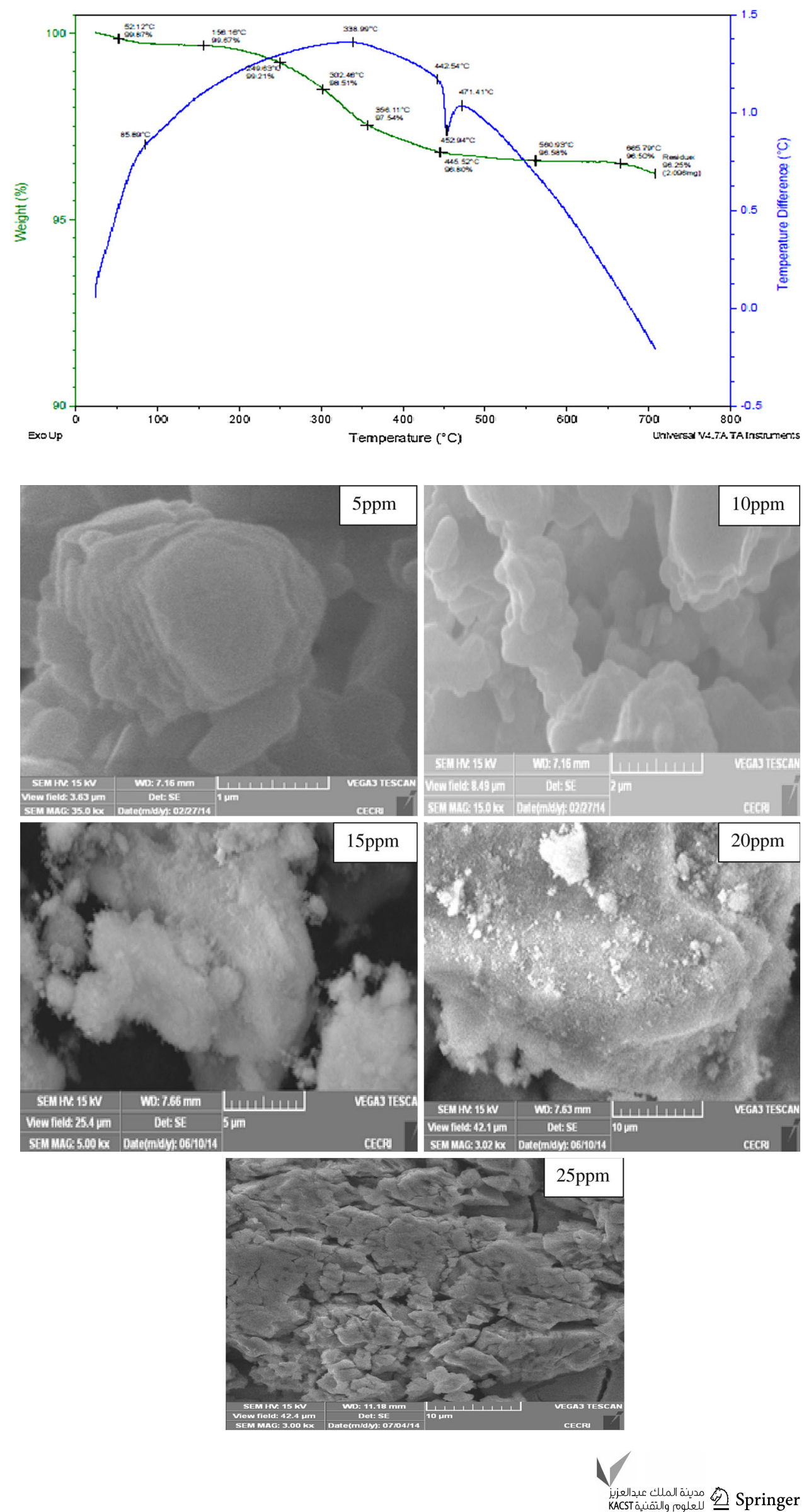
Fig. 8 XRF images of silver doped scale $\left(\mathrm{CaPO}_{4}\right)$ sample at 25 ppm concentration

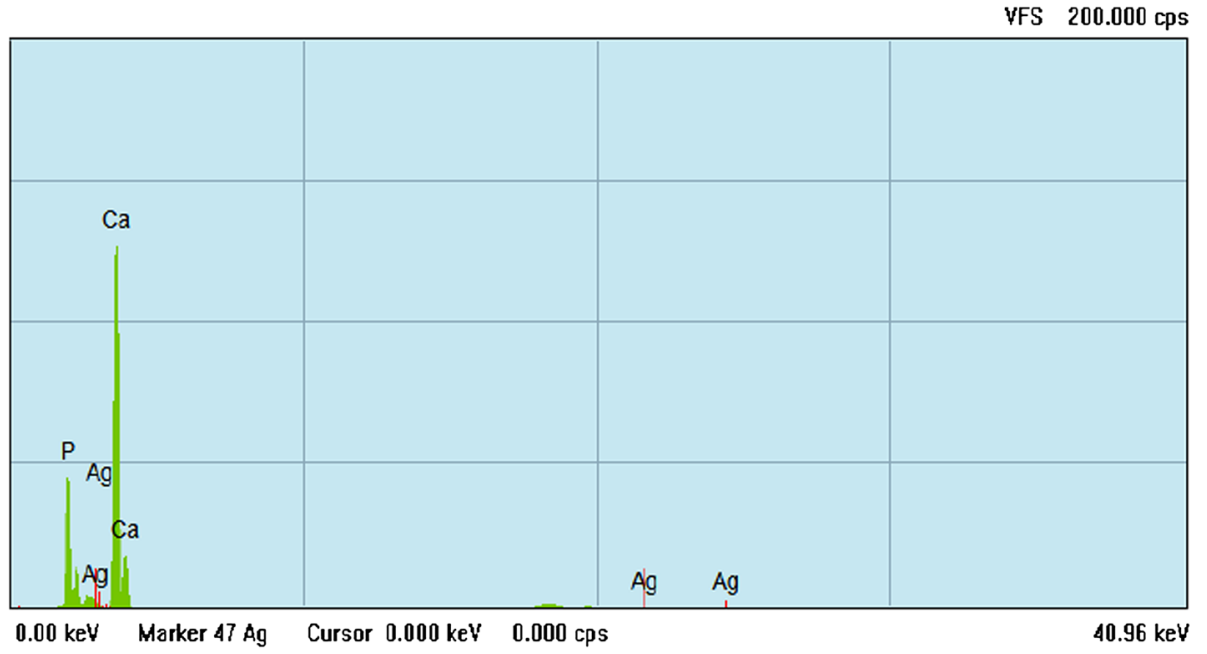

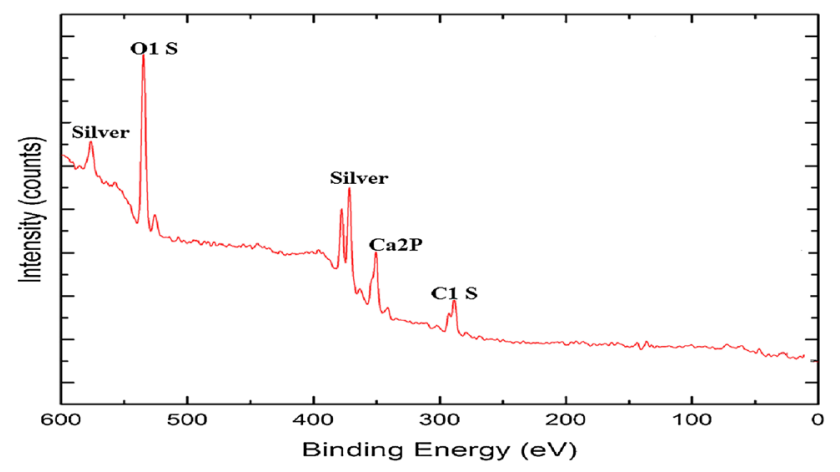

Fig. 9 XPS images of silver doped scale $\left(\mathrm{CaPO}_{4}\right)$ sample at $25 \mathrm{ppm}$ concentration

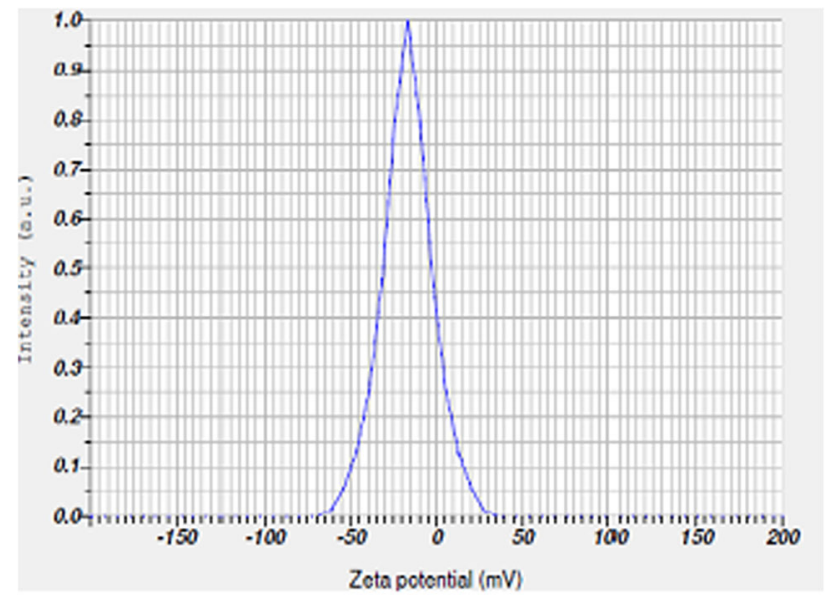

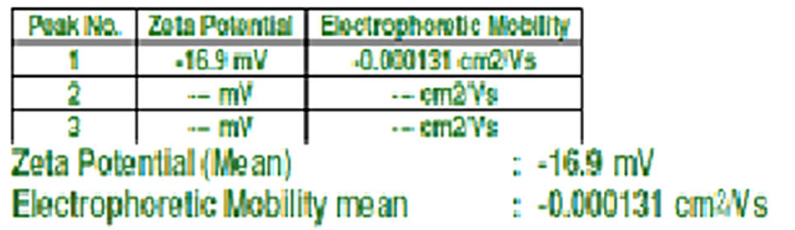

Fig. 10 Dynamic light scattering zeta potential of silver doped scale $\left(\mathrm{CaPO}_{4}\right)$ sample at $25 \mathrm{ppm}$ concentration
The possible mechanism of formation of silver doped calcium phosphate nanocomposite (Cp-Ag)

Scale formed in drinking water PVC pipelines is made up of $95 \%$ calcium phosphate and about $3 \%$ magnesium and carbonate. The nucleation of the scale (calcium phosphate) particles starts at the nanoparticle level with the deposition of calcium ions which can be reduced to nanoparticle size using the doping through solar energy. The reduced scale particles are not normally soluble in aqueous solution unless they are in critical size dimension such that the hydrophilic groups on the surface solvates the massive inorganic calcium phosphate component present in scale. But as the size of the scale particles is reduced to nano size, a larger surface area to volume ratio of the calcium phosphate is exposed revealing more hydrophilic groups. These hydrophilic functional groups on the surface of a tiny particle (of nano dimension) interact with aqueous solution through intermolecular hydrogen bonding resulting in the scale sample particles becoming soluble in solution. This is significant in that the calcium phosphate in the form of the scale is now available to take part in chemical reactions in aqueous solution which hither to was not possible. The carboxylic acid protons are deprotonated by the ammonium hydroxide base silver nitrate $\left(\mathrm{AgNO}_{3}\right)$ and are reduced to silver nanoparticles. The deprotonated carboxylic groups stabilize silver ions $\left(\mathrm{Ag}^{+}\right)$on the surface of the scale particles. Subsequently an electron transfer from the oxygen ion to the silver ion $\left(\mathrm{Ag}^{+}\right)$converts the silver ion to silver metal nanoparticle $(\mathrm{Ag} 0)$. The silver nanoparticles are evenly distributed on the surface of the scale particles except in some few places where there is particle agglomeration. It is obvious that silver nanoparticles are spontaneously adsorbed on the surface of the scale. This is similar to previous reports that the high surface energy of calcite led to the adsorption of $\mathrm{Cu}^{2+}$ ions onto its surface. 
Fig. 11 Schematic diagram representing the photo-synthesis of silver nanoparticles doped scale sample (calcium phosphate)

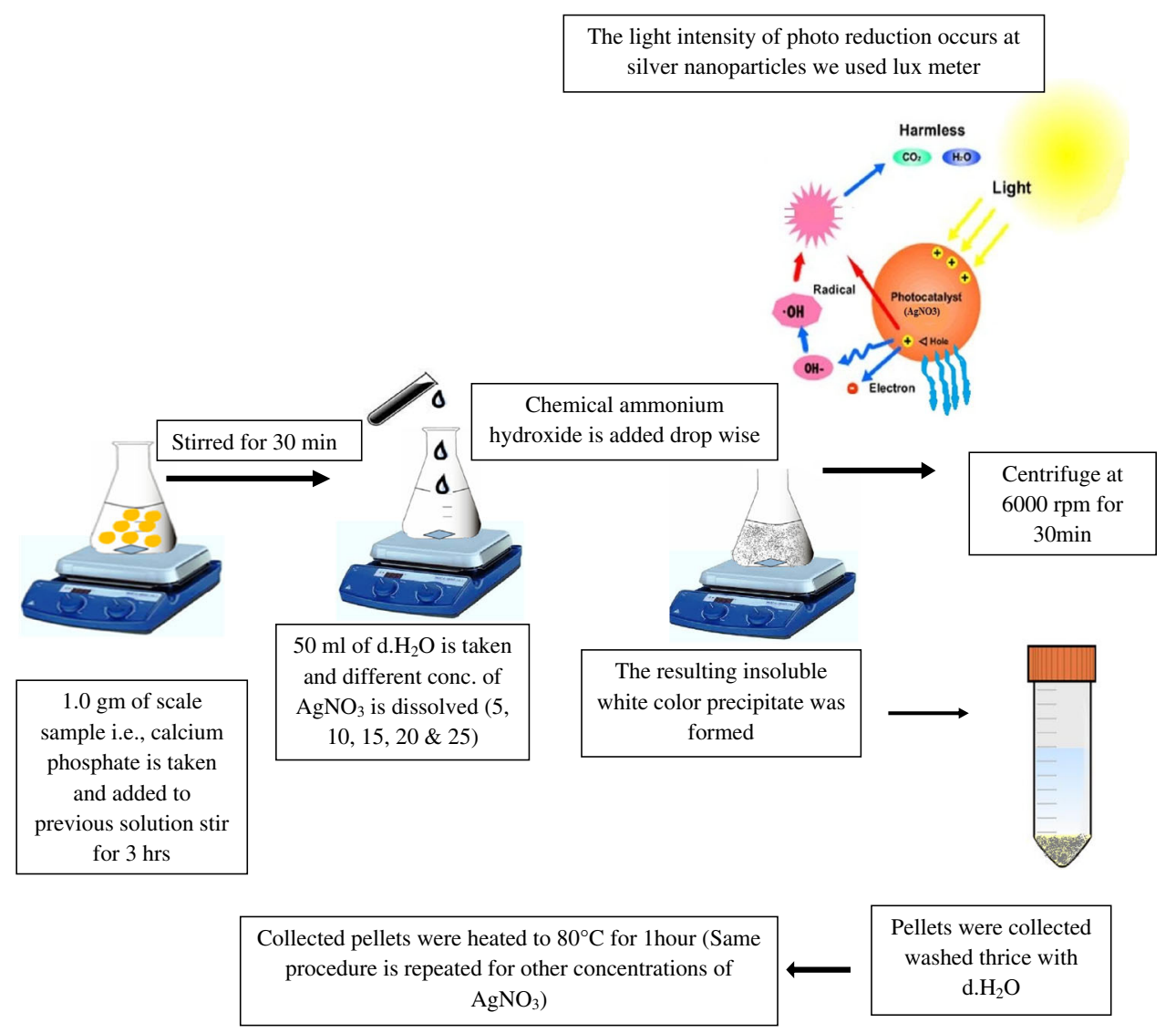

The presence of scale sample macromolecule chemical groups particularly oxygenated functional groups on the surface of the calcite particles and may preferentially direct silver nanoparticles to the surface of the micron scale calcite particles. Moreover, the size reduction of scale sample increases the surface area to volume ratio of the scale exposing new surfaces with high surface energy for attachment of the silver nanoparticles in the presence of solar energy. However, the main problem for the photo catalytic process is due to the fast recombination of the electron-hole pairs. This situation is a cause of deceasing photo catalytic activity of the photo catalyst. (Mann and Siedler 2006; Brzezinsk et al. 2008). Doping of transition metals on the photo catalyst surface as well as coupling of two photo catalysts can improve the charge-transfer and photo catalytic activity. The use of a $\mathrm{pH}$ sensitive material, calcium phosphate (scale sample) as a matrix may promote $\mathrm{pH}$ release of the silver nanoparticles and the schematic diagram of silver doped $\mathrm{CaPO}_{4}$ in the presence of photo catalytic activity was shown in (Fig. 11).

Antimicrobial study of $\mathrm{Cp}-\mathrm{Ag}$ composite material

Antimicrobial activity of silver doped scale sample was investigated by using a modified Kirby-Bauer disc diffusion assay method and the zone of inhibition for E. coli and $S$. aureus was recorded after the bacteria were exposed to various concentrations of silver viz., 5, 10, 15, 20, $25 \mathrm{ppm}$. As indicated in (Fig. 12a), the inhibitory effect with and without the composite of scale doped, where there is a maximum zone of inhibition seen in $25 \mathrm{ppm}$ and minimum zone of inhibition seen in $10 \mathrm{ppm}$ but very less zone of inhibition is seen in $5 \mathrm{mg}$ of $E$. Coli. There is a maximum zone of inhibition seen in $25 \mathrm{ppm}$ and minimum zone of inhibition seen in all other concentrations like 5, $10,15,20 \mathrm{ppm}$ in $S$. aureus. In control, there is no zone of inhibition seen (Fig. 12b, c). Consequently the silver doped scale samples nanoparticles are brought close to the bacteria resulting in direct interaction of the bacteria and the silver nanoparticles. This is due to the hydrophilic groups of the calcium particles which promotes the dispersion of the silver nanocomposite in aqueous solution. The hydrophilic nature of the composite also enables $E$. coli and $S$. aureus (Harikishore et al. 2014) adherence, facilitating silver-bacterial interaction, hence increasing the antibacterial activity. Scale sample (biofilm) based on silver doped $\mathrm{CaPO}_{4}$ will diminish adverse effects of the silver. This is significant in that it precludes the use of toxic reducing agents which could pose environmental concerns. The SEM micrographs indicate that the scale doped particles

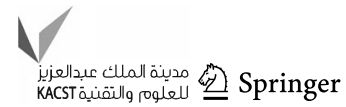




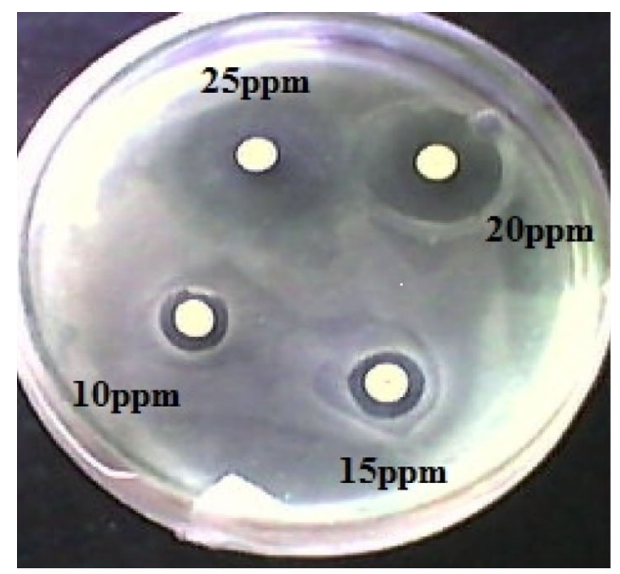

(a) Staphylococcus aureus

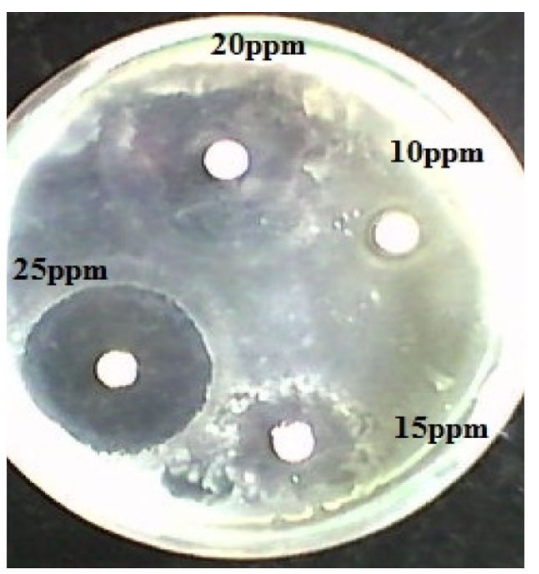

(b) E.coli

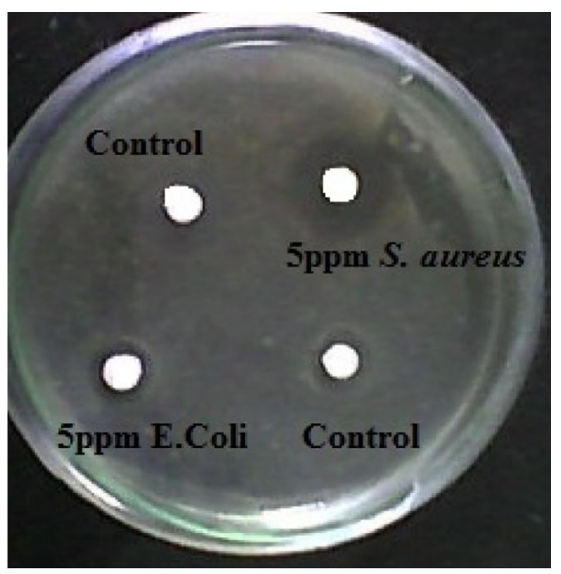

(c) Control

Fig. 12 Antibacterial activity of silver doped scale $\left(\mathrm{CaPO}_{4}\right)$ sample at different $(5,10,15,20,25 \mathrm{ppm})$ concentration (Staphylococcus aureus, E. coli and control)

Table 1 Antibacterial activity of silver doped calcium phosphate (scale sample) at different concentrations

\begin{tabular}{lll}
\hline $\begin{array}{l}\text { Concentrations of } \\
\text { silver doped } \\
\left(\mathrm{CaPO}_{4}\right)\end{array}$ & $\begin{array}{l}\text { Staphylococcus } \\
\text { aureus (zone of } \\
\text { inhibition in mm) }\end{array}$ & $\begin{array}{l}\text { Escherichia } \\
\text { coli (zone of } \\
\text { inhibition) }\end{array}$ \\
\hline Control & $0.0 \pm 0.0$ & $0.0 \pm 0.0$ \\
$5 \mathrm{ppm}$ & $2.0 \pm 0.1$ & $1.8 \pm 0.2$ \\
$10 \mathrm{ppm}$ & $2.4 \pm 0.2$ & $1.9 \pm 0.1$ \\
$15 \mathrm{ppm}$ & $2.9 \pm 0.4$ & $2.1 \pm 0.4$ \\
$20 \mathrm{ppm}$ & $3.6 \pm 0.5$ & $2.4 \pm 0.6$ \\
$25 \mathrm{ppm}$ & $4.1 \pm 0.3$ & $3.2 \pm 0.5$ \\
\hline
\end{tabular}

Each value is the $\pm \mathrm{SE}$ of three measurements

form structural support for the silver nanoparticles in the nanocomposite reduces the agglomeration of the silver nanoparticles and enhances their activity (Schosseler et al. 1999; Won et al. 2010; Bedi et al. 2012) (Table 1).

\section{Conclusion}

Highly stable Ag NPs were synthesized and embedded on the surface of the scale (calcium phosphate) sample collected from drinking water PVC pipelines at different concentrations. The antimicrobial activity of the silver doped scale $\left(\mathrm{CaPO}_{4}\right)$ was studied and compared using modified Kirby-Bauer disc diffusion zone of inhibition. The silver nanoparticles embedded on the nanocomposite ranged in size from 35 to $50 \mathrm{~nm}$. The silver nanoparticles are uniformly distributed on the surface of scale matrix with less agglomeration. The Ag doped scale nanocomposite showed superior antimicrobial properties towards E. coli (gram negative bacteria) and S. aureus (gram positive bacteria). The present study was also focused on the development of a biomaterial based on silver doped $\mathrm{CaPO}_{4}$ which is a waste product extracted from PVC pipelines which is taken and converted into useful product exhibiting antibacterial properties against Gram positive and negative bacteria, as demonstrated by our Microbiological assays. These results are encouraging us to consider that nanosilver doped scale $\left(\mathrm{CaPO}_{4}\right)$ could be used for different biomedical applications, such as the treatment of wounds and burn infections, the wound dressings and coating of bone prostheses.

Open Access This article is distributed under the terms of the Creative Commons Attribution License which permits any use, distribution, and reproduction in any medium, provided the original author(s) and the source are credited.

\section{References}

Bedi RS, Cai R, Neill CO, Beving DE, Foster S, Guthrie S, Chen W, Yan Y (2012) Hydrophilic and antimicrobial Ag-exchanged zeolite a coatings: a year-long, durability study and preliminary evidence for their general microbiocidal efficacy to, bacteria, fungus and yeast. Micropor Mesopor Mater 151:352-357

Brzezinsk P, Wellman-Labadie O, Lakshminarayanan R, Hincke MT (2008) Antimicrobial, properties of avian eggshell-specific C-type lectin-like proteins. FEBS Lett 582:699-704

Ciobanu CS, Massuyeau F, Constantin LV, Predoi D (2011) Structural and physical properties of antibacterial Ag-doped nano-hydroxyapatite synthesized at $100{ }^{\circ} \mathrm{C}$. Nanoscale Res Lett 6:613

Combes C, Rey C (2010) Amorphous calcium phosphates: synthesis, properties and uses in biomaterials. Acta Biomater 6(9):33623378

Costescu A, Pasuk I, Ungureanu F (2010) Physico-chemical properties of nano-sized hexagonal hydroxyapatite powder synthesized by sol-gel. Dig J Nanomater Biostruct 5(4):989-1000

Dahl JA, Maddux BLS, Hutchison JE (2007) Toward greener nanosynthesis. Chem Rev 107(6):2228-2269 
Edwards M, Jacobs S, Taylor R (2000) The blue water phenomenon. J Am Water Works Assoc 92(7):72-82

Feng QL, Wu J, Chen GQ, Cui FZ, Kim TN, Kim JO (2000) A mechanistic study of the antibacterial effect of silver ions on E. coli and Staphylococcus aureus. J Biomed Mater Res 52:662-668

Hamouda T, Baker JR (2000) Antimicrobial mechanism of action of surfactant lipid preparations in enteric gram-negative bacilli. J Appl Microbiol 89(3):397-403

Harikishore M, Sandhyarani M, Venkateswarlu K, Nellaippan TA, Rameshbabu N (2014) Effect of Ag doping on antibacterial and photocatalytic activity of nanocrystalline $\mathrm{TiO}_{2}$ procedia. Mater Sci 6:557-566

Hutchison JE (2008) Greener nanoscience a proactive approach to advancing applications and reducing implications of nanotechnology. ACS Nano 2(3):395-402

Jiang H, Manolache S, Wong ACL, Denes FS (2004) Plasmaenhanced deposition of silver nanoparticles onto polymer and metal surfaces for the generation of antimicrobial characteristics. J Appl Polym Sci 93(3):1411-1422

Khaydarov RR, Estrin Y, Evgrafova SE, Scheper T, Endres C (2008) Nanoparticles risk and benefits. Springer, Dordrecht
Mann k, Siedler F (2006) Amino acid sequences and phosphorylation sites of emu and, rhea egg shell C-type lectin-like proteins. Comp Biochem Phys B143:160-170

Rastogi SK, Rutledge VJ, Gibson C, Newcombe DA, Branen JR, Branen AL (2011) Ag colloids and Ag clusters over EDAPTMScoated silica nanoparticles: synthesis, characterization, and antibacterial activity against Escherichia coli. Nanomed Nanotechnol Biol Med 7(3):305-314

Renner R (2008) Pipe scales release hazardous metals into drinking water. Environ Sci Technol 42(12):4241

Schosseler PM, Wehrli B, Schweiger A (1999) Uptake of $\mathrm{Cu}^{2+}$ by the calcium, carbonates vaterite and calcite as studied by continuous wave (cw) and, pulse elctron paramagnetic resonance. Geochim Cosmochim Acta 63:1955-1967

Sharma VK, Yngard RA, Lin Y (2009) Silver nanoparticles green synthesis and their antimicrobial activities. Adv Colloid Interface Sci 145:83-96

Vallet-Regi M, Gonzalez-Calbet JM (2004) Calcium phosphates as substitution of bone tissues. Prog Solid State Chem 32:1-31

Won JY, Min J, Park J (2010) Bacteria adsorption on hydrophilic surfaces for the, sensitive detection of pathogenic bacteria using a single tube chamber system. Biosens Bioelectron 26:1763-1767 